\title{
Effectiveness of solution-focused group counseling to improve planned happenstance skills of student
}

Keefektifan solution focused group counseling untuk meningkatkan planned happenstance skills mahasiswa akhir

\author{
M Arli Rusandi ${ }^{1}$, DYP Sugiharto ${ }^{2}$, Sunawan Sunawan ${ }^{3}$ \\ ${ }^{1}$ Universitas Lambung Mangkurat, Indonesia \\ ${ }^{23}$ Universitas Negeri Semarang, Indonesia
}

\section{Article Info \\ Article history:}

Received August 29 $9^{\text {th }}, 2018$

Revised January $05^{\text {th }}, 2019$

Accepted May 25 ${ }^{\text {th }}, 2019$

\section{Keyword:}

Solution-focused

Group counseling

Planned happenstance skills

\begin{abstract}
This study aimed to determine the effectiveness of solution-focused group counseling to improve students planned happenstance skills. The experimental research method way repeated measures with pretest design and multiple posttest design, involving 5 students as participants which from 24 upperclassman of the guidance and counseling FKIP ULM which have low planned happenstance skills. The result of the research by using one-way ANOVA for repeated measures test showed that solution-focused group counseling was effective in improving the planned happenstance skills $(\mathrm{F}(2,8)$ $=325,895 ; \mathrm{p}<0,001)$.
\end{abstract}

\section{Corresponding Author:}

M Arli Rusandi,

Email: arli.rusandi@ulm.ac.id

\section{Pendahuluan}

Planned Happenstance berarti "merencanakan sebuah kebetulan". Memang kelihatan seperti sebuah kombinasi kata oxymoronic; namun ini menyoroti peran individu dalam menghasilkan kejadian sendiri dan memanfaatkan seluruh pengalaman serta sumber daya untuk memaksimalkan belajar mereka. Planned Happenstance mendorong individu untuk secara aktif mencari situasi di mana peristiwa kebetulan dapat terjadi kapan saja. Ini kemudian mendorong mereka untuk terbuka terhadap peluang dalam situasi kebetulan dan mengambil manfaat terhadap kejadian kebetulan yang terjadi.

Mitchell, Levin, dan Krumboltz (1999) menjelaskan bahwa planned happenstance theory sebagai alternatif untuk pergeseran yang cepat dalam dunia kerja dan menjelaskan "faktor kesempatan" dalam pengembangan karir individu. Meskipun peluang masa depan sering dibuat tanpa kemauan seseorang, individu dapat membuat dengan sengaja serta memanfaatkan lima komponen planned happenstance skill/PHS yaitu rasa ingin tahu/penasaran, ketekunan, fleksibilitas, optimisme, dan berani mengambil risiko. Planned happenstance skill/PHS (Krumboltz, Foley, \& Cotter, 2013) dalam kaitannya memahami sebuah kebetulan tidak hanya sebagai peristiwa kebetulan dan pengalaman, tetapi juga sebagai kemampuan individu untuk mencari peristiwa tersebut dan pengalaman yang dapat memaksimalkan belajar mereka.

Lima keterampilan tersebut sangat diperlukan mengingat persaingan dunia kerja di tahun 2017 semakin meningkat, sumber daya manusia tidak hanya dari dalam namun juga luar negeri juga ikut meramaikan bursa pencarian kerja di Indonesia. Selain itu Indonesia sudah menjajaki era revolusi industri 4.0 yang membuat berkembangnya ilmu pengetahuan dan teknologi yang tak terelakkan lagi, sehingga memfasilitasi berbagai macam inovasi. Salah satu contoh inovasi tersebut adalah terciptanya layanan transportasi online dan berkembangnya onlineshop. Hal tersebut berdampak kepada terciptanya lapangan kerja baru. Menurut 
liputan (Armindya, 2015; Syatiri, 2015) yang bergabung dalam layanan transportasi online tersebut mulai dari tuna karya, pesuruh kantoran (office boy), mahasiswa, hingga pegawai bank pun turut serta.

Penelitian yang dilakukan oleh Bright, Pryor, dan Harpham (2005) juga menyebutkan bahwa 772 siswa SMA dan mahasiswa Australia tentang peran peristiwa happenstance/kebetulan dalam pengambilan keputusan karir mereka; 69,1\% melaporkan keputusan karir mereka dipengaruhi oleh peristiwa happenstance/kebetulan. Lebih lanjut hasil penelitian Bright, Pryor, Chan, \& Rijanto (2009) menyatakan kejadian kebetulan memiliki dampak terbesar pada pengembangan karir.

Hal ini juga sejalan dengan pendapat Krumboltz (2009) bahwa PHS ini penting bagi konselor karir memfasilitasi konseli mereka tentang pentingnya terlibat dalam berbagai kegiatan yang menarik juga bermanfaat, memastikan reaksi mereka, sisanya waspada terhadap peluang alternative, dan ketrampilan belajar untuk berhasil dalam setiap kegiatan baru.

Oleh karena itu, melihat fenomena dunia perekonomian yang bergejolak tidak menentu, meningkatnya kebutuhan masyarakat, ketatnya persaingan dunia kerja dan dalam rangka membantu mengurangi pengangguran yang didominasi oleh lulusan perguruan tinggi, maka perlu ditingkatkan planned happenstance skill (PHS) mengingat masa depan seseorang tidak bisa diprediksi secara akurat, gejolak lingkungan kerja yang tidak terduga, kesempatan dan peluang kerja yang ada sehingga dengan itu individu didorang untuk menciptakan dan mengubah peristiwa yang tidak direncanakan menjadi peluang untuk belajar serta membuat rencana untuk menghasilkan dan mudah menerima peluang kesempatan.

Salah satu pendekatan konseling yang memungkinkan konselor untuk bekerja secara efektif dengan kekuatan dan sumber daya konseli yang membutuhkan bantuan dalam keputusan karir dan menyiapkan kebetulan yang direncanakan adalah solution focused brief counseling/SFBC atau apabila dibahasakan menjadi Konseling Singkat Berfokus Solusi. Tetapi didalam penelitian ini SFBC dilaksanakan dalam suasana kelompok sehingga disebut solution focused group counseling/SFGC.

SFBC adalah pendekatan konstruktivis pada tahun 1980 yang mulai dikembangkan oleh Steve de Shazer dan Insoo Kim Berg (Berg, 1994; de Shazer, 1985) untuk digunakan di bidang konseling pribadi. Model mereka, yang berorientasi pada masa depan dan menghormati keragaman klien dan perbedaan kontekstual sangat sesuai untuk bekerja dengan klien karir. Miller (2004a, 2004b, 2006, 2016), Lobby (2014) dan Burwell dan Chen (2006) menggagas SFBC diterapkan kedalam konseling karir. Sedangkan (Corey, 2012; Jacobs, Masson, Harvill, Schimmel, 2012 dan Corey, Corey, Corey, 2014) dalam literature nya menjelaskan tata laksana penerapan SFBC kedalam susana kelompok.

Beberapa peneliti yang menerapkan SFBC kedalam konseling karir diantaranya Mulawarman, Munawaroh dan Nugraheni (2016) yang menguji SFBC untuk kemampuan adaptasi karir. Selain itu beberapa penelitian berkaitan SFBC yang tidak berhubungan dengan karir diantaranya Bond, Woods, Humphrey, Symes, \& Green (2013) mereview keefektifan SFBC selama rentang 1990-2010 penelitian yang terpublikasi dan menyatakan SFBC sangat efektif sebagai intervensi awal saat menghadirkan masalah yang tidak parah. Gingerich \& Peterson (2013) menyimpulkan SFBC efektif untuk berbagai macam hasil perilaku dan psikologis selain itu juga lebih singkat dan lebih hemat daripada pendekatan alternatif. Rusandi \& Rachman (2014) yang membuktikan SFBC efektif meningkatkan self-esteem mahasiswa pasca ujian proposal skripsi. Ilbay dan Akin (2014) menguji Program Coping Burnout dengan prinsip SFBC terbukti menurunkan burnout mahasiswa.

Dalam setting kelompok, Javanmiri, Kimiaee \& Abadi (2013) dalam penelitiannya menyimpulkan konseling kelompok berfokus solusi yang dilakukan delapan sesi (satu sesi memakan waktu waktu satu jam) dapat menurunkan depresi pada remaja perempuan selainitu juga dapat dilihat betapa stabilnya pengaruh konseling kelompok berfokus solusi mengurangi depresi. Sedangkan Saadatzaade \& Khalili (2012) menyimpulkan bahwa konseling kelompok berfokus solusi dapat meningkatkan self-regulation dan prestasi akademik siswa sekolah menengah atas.

SFBC merupakan proses penyelidikan kolaboratif di mana konselor dan klien secara selektif menegaskan kualitas terbaik klien untuk mendorong tanggung jawab klien terhadap arah, evolusi dan pengelolaan tujuan karir mereka sendiri. Oleh karena itu, tujuan konselor karir yang berfokus pada solusi adalah memberi kesempatan kepada klien untuk memvisualisasikan diri mereka dalam gagasan mereka sendiri tentang masa depan karir yang positif.

Kekhasan SFBC adalah dengan adanya tools kit (scales questions, miracle question, positive exceptions) yang bisa digunakan untuk membantu konselor (Visser \& Dierolf, 2004). Selain itu (Metcalf, 1998) 
menyebutkan keuntungan SFBC diterapkan dalam setting kelompok adalah dengan banyaknya anggota kelompok maka akan semakin banyak juga masukan-masukan solusi dari anggota kelompok.

\section{Metode}

Dalam penelitian ini peneliti menggunakan rancangan repetead measure dengan desain pretest and multiple posttest design. Dalam rancangan ini seluruh seluruh partisipan dalam suatu kelompok tunggal berpartisipasi di semua perlakuan eksperimental, dimana setiap kelompok menjadi kontrolnya sendiri. Sampel penelitian adalah 5 orang yang dipilih secara purposive dari 24 orang mahasiswa semester 8 Prodi BK FKIP ULM yang memiliki planned happenstance skills rendah.

Intervensi yang digunakan adalah Solution focused group counseling. Dalam hal ini peneliti mencoba mengeksplorasi dan mengelaborasi tahapan yang dikemukakan oleh Corey (2012) dengan mempertimbangkan kearifan lokal (local wisdom) dalam pelaksanaannya sehingga dapat secara fleksibel disesuaikan dengan kebutuhan-kebutuhan kelompok tanpa mengikis nilai-nilai khas Indonesia. Corey (2012: 70 - 71) menyatakan tahapan konseling kelompok terbagi menjadi 6 tahap yaitu; tahap pembentukan (the formation stage); tahap orientasi (the orientation phase); tahap transisi (the transition stage); tahap kerja (the working stage); tahap konsolidasi (the consolidation stage); evaluasi dan tindak lanjut (evaluation and follow-up issues).

Solution focused group counseling dilaksanakan sebanyak 4 kali pertemuan dengan intensitas pertemuan $2 \times 50$ ' setiap minggu. Setelah dua minggu anggota kelompok diberikan kembali posttest2 guna melihat kekonsistenan anggota kelompok dalam penelitian ini.

\begin{tabular}{|c|}
\hline Pretest \\
\hline Solution focused group counseling \\
\hline Posttest1 \\
\hline Posttest 2 \\
\hline
\end{tabular}

Gambar 1. Tahapan Penelitian

Teknik pengumpulan data yang digunakan dalam penelitian ini adalah menggunakan skala Planned Happenstance Career Inventory (PHCI) yang dikembangkan oleh Kim, Jung, Jang, Lee, Rhee, Cho, \& Lee (2014), berdasarkan Planned Happenstance Theory yang dikembangkan oleh (Mitchell, Levin, dan Krumboltz (1999). PHCI memiliki lima subskala, yaitu rasa ingin tahu, ketekunan, fleksibilitas, optimisme, dan pengambilan risiko yang terdiri dari 25 item. Pada skala tersebut, peneliti melakukan equivalence (kesetaraan) dengan melakukan proses backtranslation, validasi ahli dan kemudian uji coba instrumen. Hasil uji instrumen, semua item dinyatakan valid $\left(\mathrm{r}_{\mathrm{xy}}: 0,298-0,642\right)$, dengan koefisian alpha sebesar 0,874 . Data yang didapatkan selanjutnya dianalisis dengan menggunakan uji the one-way ANOVA for repeated measures.

\section{Hasil dan Pembahasan}

Hasil analisis dengan menggunakan repeated measures terdapat perbedaan sebelum dan sesudah diberikan treatment $(\mathrm{F}(2,8)=325,895 ; \mathrm{p}<0,001)$. Nilai rata-rata planned happenstance skills mengalami peningkatan pada pretest, posttest 1 dan posttest2. Dari penjelasan tersebut dapat disimpulkan bahwa bahwa solution focused group counseling efektif dalam meningkatkan planned happenstance skills. Untuk lebih jelasnya dapat dilihat pada tabel 1 .

Tabel 1. Hasil Uji Hipotesis Planned Happenstance Skills Semester 8 Prodi BK FKIP ULM

\begin{tabular}{cccccc} 
& Pretest & Posttest1 & Posttest2 & F (2.8) & p \\
\hline Mean & 52,2 & 87,4 & 90 & 325,895 & $<0,001$ \\
SD & 1,483 & 5,413 & 4,301 & & \\
\hline
\end{tabular}


Selanjutnya signifikansi efektifitas layanan konseling kelompok solution focused group counseling dapat dilihat pada tabel 2. Hasil dari perhitungan pairwise comparisons planned happenstance skills menunjukkan perbedaan nilai rata-rata pretest-posttest2 lebih besar dibandingkan pretest-posttest1, sedangkan perbedaan nilai rata-rata posttest1-posttest2 tidak signifikan.

Tabel 2. Planned Happenstance Skill Mahasiswa Semester 8 Program Studi Bimbingan Dan Konseling FKIP ULM Banjarmasin

\begin{tabular}{|c|c|c|}
\hline Perbandingan & $M D$ & $S E$ \\
\hline Pretest-Posttest1 & $-29,200^{*}$ & 1,855 \\
\hline Pretest-Posttest2 & $-31,800^{*}$ & 1,356 \\
\hline Posttest1-Posttest2 & $-2,600$ & 0,678 \\
\hline
\end{tabular}

Mengacu pada hasil penelitian di atas, maka apa yang ditemukan dalam penelitian ini sejalan dengan pendapat Miller (2004a, 2004b, 2006, 2016) yang menyebutkan bahwa SFBC bias diterapkan dalam konseling karir. Sehingga memperkuat hasil riset terdahulu bahwa SFBC cukup dapat diandalkan dalam konselin karir dan merupakan salah satu strategi mutakhir dalam layanan bimbingan karir (Looby, 2014).

Hasil penelitian tersebut juga sesuai dengan penelitian terkait. Penelitian yang dilakukan oleh Gong dan Hsu (2016) juga membuktikan tingkat keefektifan SFGC yang tinggi dalam setting sekolah pertama etnis China untuk menginternalisasi masalah perilaku dan untuk masalah keluarga serta hubungan pertemanan. Sedangkan Sari (2016) dalam artikelnya mengkaji tentang kemungkinan SFGC untuk mengurangi perilaku agresif.

Penelitian Wijayanti (2016) menunjukkan hasil bahwa konseling kelompok secara signifikan mampu meningkatkan efikasi diri dalam pengambilan keputusan karir pada siswa SMA. Ateş (2016) dalam penelitiannya membuktikan solution-focused brief group counseling efektif untuk meningkatkan tingkat kompetensi sosial yang dirasakan remaja. Penelitian Khadivi \& Namani (2016) memperoleh temuan bahwa SFBC dalam setting kelompok dapat menyebabkan penurunan burnout yang signifikan pada wanita yang memiliki suami bukan pecandu (alkohol atau obat-obatan). Wiyono (2015) solution focused group counseling terbukti efektif untuk meningkatkan motivasi berprestasi siswa SMK. Sedangkan Ateş (2016) membuktikan bahwa solution focused group counseling efektif untuk siswa SMA yang berjuang mengatasi burnout di sekolah.

\section{Kesimpulan}

Penelitian ini dilakukan untuk melihat keefektifan solution focused group counseling dalam meningkatkan planned happenstance skills mahasiswa semester 8 Prodi BK FKIP ULM. Hasil penelitian yang telah dilakukan menunjukkan solution focused group counseling efektif secara signifikan dalam meningkatkan planned happenstance skills mahasiswa. Hal ini berdasarkan kepada hasil pretest dan posttest pada skala Planned Happenstance Career Inventory (PHCI) mahasiswa sebelum dan sesudah diberikan layanan. Selanjutnya hasil dari Pairwise Comparisons planned happenstance skills mahasiswa semester 8 Prodi BK FKIP ULM juga menunjukkan signifikansi efektifitasnya.

\section{Referensi}

Armindya, Y. R. (2015). Banyak Sarjana Jadi Pengemudi Gojek, Ternyata Ini Alasannya. https://m.tempo.co/read/news/2015/08/15/083692106/banyak-sarjana-jadi-pengemudi-gojekternyata-ini-alasannya (diunduh 17 April 2017).

Ate, B. (2016). "Effect of Solution Focused Group Counseling for High School Students in Order to Struggle with School Burnout". Journal of Education and Training Studies, 4(4): 27-34.

Berg, I. K. (1994). Family-Based Services: A Solution-Focused Approach. New York: Norton.

Bond, C., Woods, K., Humphrey, N., Symes, W., \& Green, L. (2013). "Practitioner Review: The Effectiveness of Solution Focused Brief Therapy with Children and Families: A Systematic and Critical Evaluation of the Literature from 1990-2010". Journal of Child Psychology and Psychiatry, 54(7), 707723.

Bright, J. E., Pryor, R. G., \& Harpham, L. (2005). "The Role ff Chance Events in Career Decision Making". 
Journal of Vocational Behavior, 66(3): 561-576.

Bright, J. E., Pryor, R. G., Chan, E. W. M., \& Rijanto, J. (2009). "Chance Events in Career Development: Influence, Control and Multiplicity". Journal of Vocational Behavior, 75(1): 14-25.

Gingerich, W. J., \& Peterson, L. T. (2013). "Effectiveness of Solution-Focused Brief Therapy a Systematic Qualitative Review of Controlled Outcome Studies". Research on Social Work Practice, 23(3): 266283.

Gong, H., \& Hsu, W. (2016). "The Effectiveness of Solution-Focused Group Therapy in Ethnic Chinese School Settings: A Meta-Analysis". International Journal of Group Psychotherapy, 1-27.

Ilbay, A. B., \& Akin, A. (2014). "The Impact of Solution-Focused Brief Group Psychological Counseling on University Students' Burnout Levels”. Üniversitepark Bülten| Universitepark Bulletin.

Javanmiri, L., Kimiaee, S. A., \& Abadi, B. A. G. H. (2013). "The Study of Solution- Focused Group Counseling in Decreasing Depression among Teenage Girls". International Journal of Psychological Studies. 5(1):105-111.

Khadivi, E., \& Namani, E. (2016). "Effectiveness ff Short-Term Solution-Focused Group Training in Couple Burnout Among the Spouses of People Freed from Addiction". International Journal of Medical Research \& Health Sciences, 5(9): 262-267.

Kim, B., Jung, S. H., Jang, S. H., Lee, B. H., Rhee, E., Cho, S. H., \& Lee, S. M. (2014). "Construction and Initial Validation of the Planned Happenstance Career Inventory". The Career Development Quarterly, 62: 239-253.

Krumboltz, J. D. (2009). "The Happenstance Learning Theory". Journal of Career Assessment, 17: 135-154.

Krumboltz, J. D., Foley, P. F., \& Cotter, E. W. (2013). "Applying the Happenstance Learning Theory to Involuntary Career Transitions". The Career Development Quarterly, 61(1): 15-26.

Looby, M. A. (2014). Solution-Focused Career Counseling. https://associationdatabase.com/aws/NCDA/pt/sd/news_article/89853/_PARENT/layout_details_ cc/true (diunduh 13 April 2017).

Metcalf, L. (1998). Solution Focused Group Therapy: Ideas for Groups in Private Practice, Schools, Agencies, And Treatment Programs. Simon and Schuster.

Miller, J. (2006). "Using A Solution-Building Approach in Career Counselling" dalam McMahon, M., dan Patton, W. (Ed.), Career counselling: Constructivist approaches USA: Routledge. 123-136.

Miller, J. (2016). "Solution-Focused Career Counselling" dalam McMahon, M. (Ed.), Career Counselling: Constructivist Approaches. New York: Routledge. Hlm. 127-138.

Miller, J. H. (2004a). "Extending the Use of Constructivist Approaches in Career Guidance and Counselling: Solutionfocused Strategies". Australian Journal of Career Development, 13(1): 50-59.

Miller, J. H. (2004b). "Building a Solution-Focused Strategy into Career Counselling". New Zealand Journal of Counselling, 25(1): 18-30.

Mitchell, K. E., Levin, S. A., \& Krumboltz, J. D. (1999). "Planned Happenstance: Constructing Unexpected Career Opportunities". Journal of Counseling \& Development, 77: 115-124.

Mulawarman, M., Munawaroh, E., \& Nugraheni, E. P. (2016). "Effectiveness of Solution Focus Brief Counseling Approach (SFBC) in Developing Student Career Adaptability". COUNS-EDU/The International Journal of Counseling and Education, 1(1): 10-15.

Rusandi, M. A., \& Rachman, A. (2014). "Efektifitas Konseling Singkat Berfokus Solusi (Solution Focused Brief Therapy) Untuk Meningkatkan Self Esteem Mahasiswa Program Studi Bimbingan Konseling FKIP Unlam Banjarmasin. AL'ULUM, 62(4): 22-28.

Saadatzaade, R., \& Khalili, S. (2012). "Effects of Solution-Focused Group Counseling on Student's SelfRegulation and Academic Achievement". International Journal for Cross- Disciplinary Subjects in Education, 3(3): 780-787.

Sari, D. K. (2016). "Solution Focus Brief Group Counseling: Model Konseling Untuk Mengurangi Perilaku Agresif Siswa" dalam Pastini, S., Naqiyah, N., Mumpuniarti \& Soetarno (Ed.), Prosiding Seminar Nasional Bimbingan dan Konseling "Konseling Krisis". Yogyakarta: Prodi Bimbingan dan Konseling. Hlm. 159-172.

Sawitri, A. A. (2016). BPS: Pengangguran Terbuka di Indonesia Capai 7,02 Juta Orang. https://m.tempo.co/read/news/2016/05/04/173768481/bps-pengangguran-terbuka-di-indonesiacapai-7-02-juta-orang (diunduh 07 Maret 2017).

Visser, C., \& Dierolf, K. (2004). Realistic Career Guidance. http://sfio.org/wpcontent/uploads/2016/02/Realistic-Career-Guidance.pdf (diunduh 12 April 2017).

Wiyono, B. D. (2015). "Keefektifan Solution-Focused Brief Group Counseling Untuk Meningkatkan Motivasi Berprestasi Siswa Sekolah Menengah Kejuruan". Jurnal Konseling Indonesia, 1(1): 36-46. 